\title{
Combined heat and power-optimal power flow based on thermodynamic model with associated petroleum and wet gas utilization constraints
}

\author{
Priambudi Pujihatma ${ }^{1}$, Sasongko Pramono Hadi ${ }^{2}$, Sarjiya $^{3}$, Tri Agung Rohmat ${ }^{4}$ \\ ${ }^{1,2,3}$ Department of Electrical Engineering and Information Technology, Universitas Gadjah Mada, Indonesia \\ ${ }^{4}$ Department of Mechanical \& Industrial Engineering, Universitas Gadjah Mada, Indonesia
}

\begin{tabular}{l} 
Article Info \\
\hline Article history: \\
Received Feb 1, 2017 \\
Revised Jul 31, 2018 \\
Accepted Aug 13, 2018 \\
\hline
\end{tabular}

Keywords:

Associated petroleum gas Combined heat and power Mixed integer nonlinear programming Optimal power flow Unit commitment

\begin{abstract}
Oil fields produce associated petroleum and wet gas, which can be mixed with commercial natural gas as fuel. Associated petroleum and wet gas are a low cost, low quality fuel, whereas commercial natural gas is the opposite. Two parameters are affected by this mixture: the fuel cost and the power steam output of gas turbine - heat recovery steam generators. This research develops a Unit Commitment and Optimal Power Flow model based on Mixed Integer Nonlinear Programming to optimize combined heat and power cost by considering the optimal mixture between associated petroleum - wet gas and commercial natural gas. A thermodynamic model is used to represent the performance of gas turbine-heat recovery steam generators when subjected to different fuel mixtures. The results show that the proposed model can optimize cost by determining the most efficient power - steam dispatch and optimal fuel mixture. Furthermore, the optimization model can analyse the trade-off between power system losses, steam demand and associated - wet gas utilization.
\end{abstract}

Copyright (C) 2019 Institute of Advanced Engineering and Science. All rights reserved.

\section{Corresponding Author:}

Sasongko Pramono Hadi,

Department of Electrical Engineering and Information Technology,

Universitas Gadjah Mada,

Jl. Grafika No.2, Yogyakarta, Indonesia.

Email: sasongko@ugm.ac.id

\section{INTRODUCTION}

Associated petroleum gas (APG) is natural gas that is produced as an oil field by-product. APG can be dissolved in oil or accumulated as a gas cap inside the oil reservoir [1]. In addition to APG, oil fields produce wet gas from small size/marginal gas reserves. Due to the high gas processing cost and low gas quantity, wet gas and APG are used as fuel in oil field operations [1,2]. In a conventional operation, APG used to be flared. Due to environmental constraints, oil companies must find a way to monetize APG and wet gas, with gas to wire (GTW) electricity generation as one promising alternative [3].

APG quality is much lower compared to commercial natural gas. It has low heating content, high inert, high hydrogen sulfide and unstable volume and composition. The direct use of APG and wet gas as power generation fuel is limited by its low methane content and unstable gas composition. Wet gas contains higher hydrocarbons which can cause thermal regime failure in gas turbines [4]. The low heat content of APG and wet gas may affect the gas turbine's performance. A gas turbine requires a higher mass flow of APG and wet gas compared to natural gas to produce the same power output [2]. Thus, APG and wet gas can be combined with commercial natural gas to minimize the effect on turbine parts and maintain reliable performance.

Several studies investigate the use of low quality gas for power generation. Panjaitan [5] conducted an experiment of running a generator with biogas fuel. The result showed that the generator output power has 
lower frequency when compared to high quality fuel. In terms of associated and wet gas utilization, Anosike [2] conducted a techno-economic study to evaluate APG utilization for power plants. Watanabe [6] proposed a gas turbine combined cycle system with high-voltage direct current (HVDC) transmission to monetize associated and stranded gas reserves. Arutyunov [7] proposed the conversion of APG to syngas for better performance. Gorbachev [8] utilized 2.5 and $6 \mathrm{MW}$ gas turbine generators fueled by APG. Guryanov [9] conducted a thermo-physical analysis of a combustion chamber and engine operation and made recommendations on conditions and restrictions on gas turbines running with APG. Vanadzina [10] proposed power generation as an effective solution for APG utilization in the reformed electricity market. Rajovic [11] conducted a life cycle assessment of APG utilization for combined heat power plants and heat boilers in an oil field. Although extensive research has been done, to the best of our knowledge, there has not been any study related to power \& steam dispatch optimization that considers multiple fuel streams: APG, wet gas and commercial natural gas.

A mature oil field utilizes an enhanced recovery method where the produced steam is injected into the ground to reduce oil viscosity and ease the oil flow to the surface. Combined heat and power (CHP) system produces steam by utilizing hot exhaust gas from the gas turbine. The thermal efficiency of this system is very high, up to $80 \%$ compared to $36-50 \%$ of open cycle power generation [12]. This scheme can be implemented by connecting heat recovery steam generators (HRSG) to a gas turbine exhaust. Some HRSGs are equipped with additional duct burners (DB) to increase steam production. In addition to the CHP system, steam is also produced from gas-fired boilers.

In previous studies, CHP optimization is based on empirical objective functions and constraints. Roijers and Amerongen [13] model the objective function, fuel vs. power and steam, as a second order polynomial. The thermodynamic process constraint is modeled by Guo [14] using feasible operating regions (FOR) which comprise several linear equations. Heuristic and deterministic methods have been used to solve CHP optimization. Some examples of heuristic algorithms to address the CHP problem are as follows: ant colony [15], evolutionary programming [16, 17], particle swarm optimization [18, 21], self-adaptive genetic algorithm [19], bee colony [20], opposition-based group search [22], differential evolution [23] and gravitational search algorithm [24, 25]. Some deterministic methods that have been implemented for CHP optimization are linear programming [26], Lagrangian relaxation [27], and Bender's decomposition [28]. Shi [29] and Abdullah [30] included power system losses as constraints of CHP optimization. Kim [31] introduced a thermodynamic model in a combined heat and power economic dispatch (CHPED) in which objective function is to maximize revenue by exporting electricity in a deregulated market. These studies use a constant and predefined fuel price with a single fuel source. The effect of fuel mixture has not been discussed as yet and it is assumed that all gas turbines and HRSGs have a single fuel source of a constant quality.

This research focuses on combined heat and power (CHP) optimization with multiple fuel sources: commercial natural gas, APG and wet gas in a mature oil field operation. For convenience, the term "field gas" will be used to represent APG and wet gas. The term "natural gas" will be used to represent commercial natural gas.

The contribution of this research is a Unit Commitment and Optimal Power Flow analysis with the following novelties:

a. The use of thermodynamic model which considers multiple streams of fuel input: natural and field gas. For processes that operate over a wide range of operating condition, empirical models are unsuitable to represent the process dynamics [31]. The empirical model on fuel vs. power vs. heat produced can no longer give a close approximation, since a field and natural gas mixture may have a large variance of gas compositions and heating content.

b. Previous unit commitment problems have dealt with load demand, renewable generation, unit availability and energy prices as uncertainties [32]. This optimization model will deal with new uncertainty factor, which is the fuel mixture between high-quality high-price natural gas with lowquality low-price field gas. The fuel cost will depend on optimum fuel mixture.

c. A model that is able to analyze the tradeoffs between steam production, power system losses and field gas utilization. Steam production depends on power dispatch, which will affect the power system voltage profile and losses. Power dispatch depends on fuel quality, which is determined by mixture between natural and field gas.

The case studies use a simplified CHP system in one of South East Asia's oil field. 


\section{RESEARCH METHOD}

\subsection{System overview}

The system consists of 21 gas turbines, 5 HRSGs without duct burners and 3 HRSGs with duct burners. The gas turbines supply an island power system with $450 \mathrm{MW}$ average load, 13 substations, three voltage levels: $230,115,13.8 \mathrm{kV}$, and $280 \mathrm{~km}$ length of transmission lines. Table 1 shows gas turbine capabilities, base load heat rate and steam production capabilities. Figure 1 shows the single line diagram.

Table 1. Gas Turbine Generator Capability, Steam Production Capability and Heat Rate

\begin{tabular}{|c|c|c|c|c|c|c|c|}
\hline Unit & TYPE & $\begin{array}{l}\text { NO. OF } \\
\text { UNITS }\end{array}$ & $\begin{array}{l}\text { ACTIVE } \\
\text { POWER } \\
(\mathrm{MW})\end{array}$ & $\begin{array}{l}\text { Reactive } \\
\text { Power } \\
\text { (MVAR) }\end{array}$ & $\begin{array}{l}\text { Base load } \\
\text { Heat rate } \\
(\mathrm{GJ} / \mathrm{MWH})\end{array}$ & $\begin{array}{c}\text { Steam } \\
\text { Prod. } \\
\left(\mathrm{m}^{3} \text { cwepd }\right)\end{array}$ & Fuel \\
\hline DG 1-3 & Gas Turbine Type 1 & 3 & 100 & 75 & 10.44 & 15,900 & NG \\
\hline AG1-5 & Gas Turbine Type 2 & 5 & 25 & 18 & 11.94 & 1,590 & $\mathrm{NG}+\mathrm{FG}$ \\
\hline CG & Gas Turbine Type 2 & 1 & 25 & 18 & 11.94 & & NG \\
\hline MG1-5 & Gas Turbine Type 3 & 5 & 15 & 12 & 15.14 & & $\mathrm{NG}+\mathrm{FG}$ \\
\hline MG6-8 & Gas Turbine Type 2 & 3 & 25 & 18 & 11.94 & & $\mathrm{NG}+\mathrm{FG}$ \\
\hline MG9-11 & Gas Turbine Type 4 & 3 & 38 & 26 & 11.45 & & $\mathrm{NG}+\mathrm{FG}$ \\
\hline GB & Gas Boiler & 10 & - & - & - & 795 & $\mathrm{NG}$ \\
\hline
\end{tabular}

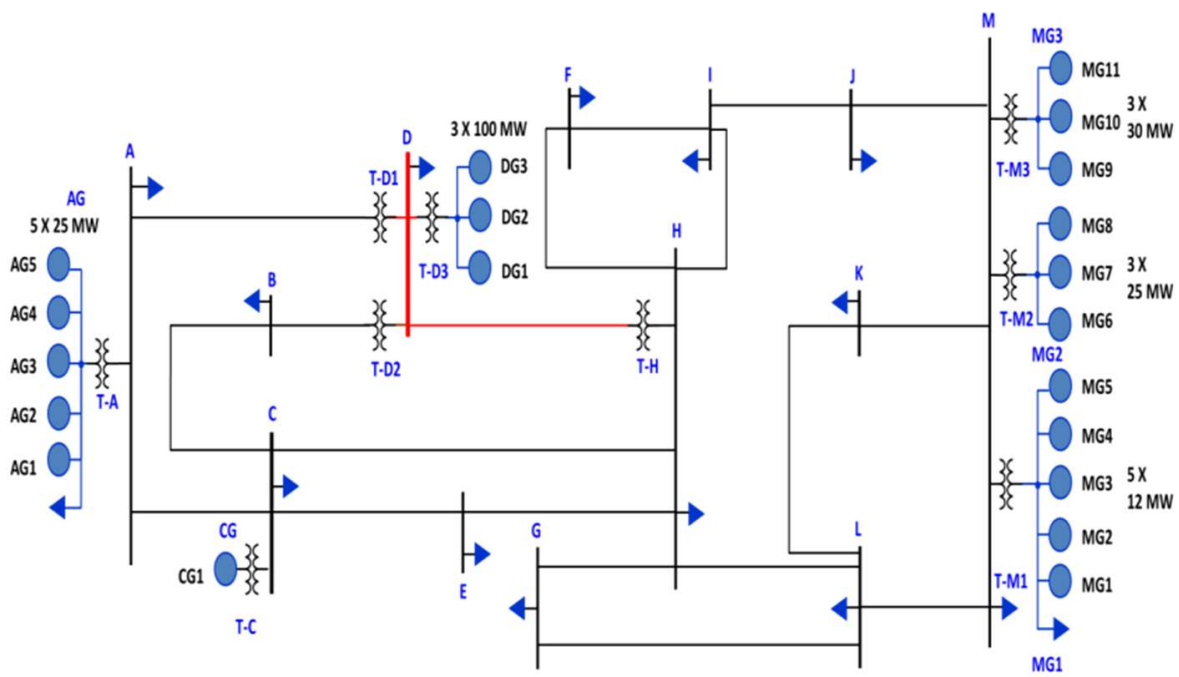

Figure 1. Simplified single line diagram

There are four gas turbine types in the system: Types 1-4, with different capabilities and base load heat rate. The base load heat rate indicates gas turbine efficiency. The most efficient gas turbine is DG1-3 (Gas Turbine Type 1), while the least efficient is MG1-5 (Gas Turbine Type 3). The gas turbines are divided into six groups; each group comprises identical gas turbines. For example, MG 1-5 consists of five identical Type 3 gas turbines. Gas turbines AG 1-5 and DG 1-3 have the capability to produce steam. DG 1-3 have additional duct burners installed to produce more steam. Ten gas-fired boilers (GB) are also utilized to produce steam.

Gas turbines AG1-5, MG1-5, MG6-8, MG9-11 have two fuel sources: natural gas and field gas. Other gas turbines and gas boilers only have natural gas as single fuel source. Each field gas stream has an average production volume, shown in Table 2 . Total field gas production volume is 37,357 cubic meters per hour at standard condition $\left(15^{\circ} \mathrm{C}\right.$ temperature, $1 \mathrm{~atm}$ pressure $)$. Table 2 shows significant difference between natural and field gas in terms of heating value.

Table 2. Natural and Field Gas Data towards AG1-5, MG1-5, MG6-11

\begin{tabular}{lccccc}
\hline \multirow{2}{*}{ Parameter } & Unit & Natural & Field Gas & Field Gas & Field Gas \\
& & Gas & AG1-5 & MG1-5 & MG6-11 \\
\hline Density (std) & $\mathrm{kg} / \mathrm{m}^{3}$ & 0.785 & 0.928 & 0.96 & 1.282 \\
Volume (std) & $\mathrm{m}^{3} / \mathrm{hour}$ & swing & 15,612 & 4,130 & 17,615 \\
Low Heating Value (mass) & $\mathrm{kJ} / \mathrm{kg}$ & 44,821 & 32,394 & 30,932 & 20,466 \\
\hline
\end{tabular}




\subsection{Gas and thermodynamic analysis}

Firstly, the optimization model analyzes the composition of each gas stream (natural gas and field gas). The net heating value per mass unit is calculated as follows:

$$
L H V_{m, m i x}=\frac{w_{N G}}{w_{N G}+w_{F G}} L H V_{m, N G}+\frac{w_{F G}}{w_{N G}+w_{F G}} L H V_{m, F G}
$$

Subscript NG and FG correspond to natural gas and field gas, respectively. Mass flow for natural and field gas is the optimization's control variable. Then, the LHV value becomes the input for GT-HRSG thermodynamic equations. GT-HRSG thermodynamic equations are based on the model proposed by Kim [31]. The model calculates the final output of the gas turbines and HRSG in terms of power and steam.

\subsubsection{Gas turbine model}

The gas turbine is modeled using the following formulas.

a. Air mass flow entering compressor $(\mathrm{kg} / \mathrm{s})$ :

$$
W_{c}=\left(\frac{M W_{\text {air }}}{R_{g}}\right)\left(\frac{P_{c} V_{c}}{T_{c}}\right)
$$

b. Air volumetric flow $\left(\mathrm{m}^{3} / \mathrm{s}\right)$ :

$$
V_{c}=V_{c n} \frac{\sin \left(\theta_{I G V}-\theta_{\min }\right)}{\sin \left(\theta_{\max }-\theta_{\min }\right)}
$$

c. Compressor outlet temperature $(\mathrm{K})$ :

$$
T_{d}=T_{c}\left(1+\frac{x_{c}-1}{\eta_{c}}\right) \quad x_{c}=\left(P R \frac{W_{c}}{W_{c n}}\right)^{\frac{\gamma_{c}-1}{\gamma_{c}}}
$$

d. Turbine inlet temperature $(\mathrm{K})$ :

$$
T_{f}=T_{d}+\left(\frac{\eta_{c o m b} L H V_{m, m i x}}{C_{p h}}\right)\left(\frac{w_{f, G T}}{w_{f, G T}+W_{c}}\right) \quad w_{f, G T}=w_{F G}+w_{N G}
$$

The gas composition and mass flow play an important role in determining $L H V_{m, m i x}$ value.

e. Turbine outlet temperature $(\mathrm{K})$

$$
T_{e}=T_{f}\left(1-\left(1-\frac{1}{x_{h}}\right) \eta_{t}\right) \quad x_{h}=\left(P R \frac{w_{f, G T}+W_{c}}{w_{f, G T n}+W_{c n}}\right)^{\frac{\gamma_{h}-1}{\gamma_{h}}}
$$

Compressor and turbine efficiency is assumed constant throughout the operating region.

f. Gas turbine power output (MW):

$$
P_{G T}=\left[\left(W_{c}+w_{f, G T}\right) C_{p h}\left(T_{f}-T_{e}\right)-W_{c} C_{p c}\left(T_{d}-T_{c}\right)\right] / 1000
$$

Fuel consumption can be converted to volume (standard meter cubic per second) as given:

$$
V_{F G}=w_{F G} / \rho_{F G} \quad V_{N G}=w_{N G} / \rho_{N G}
$$

\subsubsection{HRSG and duct burner model}

HRSG and the duct burner are modelled with these formulas:

a. HRSG inlet temperature (K):

$$
\begin{array}{ll}
T_{I N}=T_{e}+\frac{\beta_{H}}{\alpha_{H}}\left(\frac{w_{f, D B}}{w_{f, D B}+w_{f, G T}+W_{c}}\right) & \\
\alpha_{H}=\eta_{H R S G} C_{p h} & \beta_{H}=\eta_{H R S G} \eta_{D B} L H V_{m, \text { mix }}
\end{array}
$$

for HRSGs which are not equipped with duct burners, the value of $w_{f, D B}=0$. 
b. HRSG steam production $(\mathrm{kg} / \mathrm{s})$ :

$$
W_{S H}=\frac{\alpha_{H}\left(W_{c}+w_{f, G T}+w_{f, D B}\right)\left(T_{I N}-T_{E X}\right)}{H_{S H}-H_{E C}}
$$

c. HRSG steam production can be converted to cold water equivalent meter cubic per second by using cold water density value at $1000 \mathrm{~kg} / \mathrm{m}^{3}$ :

$$
W_{S V H}=W_{S H} / 1000
$$

\subsubsection{Gas-fired boiler model}

The gas-fired boiler is modelled as follows:

a. Gas boiler steam production $(\mathrm{kg} / \mathrm{s})$

$$
W_{S B}=\frac{\alpha_{G B} w_{f, G B}}{H_{S H}-H_{E C}} \quad \alpha_{G B}=\eta_{G B} L H V_{m, N G}
$$

b. Gas boiler steam production converted to cold water equivalent meter cubic per second:

$$
W_{S V B}=W_{S B} / 1000
$$

\subsection{Optimization formulation}

In general, optimization is divided into two stages:

a. Unit Commitment: to determine which gas turbine and gas-fired boiler units should be on/off based on predicted load and steam demand. The gas turbine, HRSG and gas boiler on / off status becomes input for the next optimization stage (Optimal Power Flow).

b. Optimal Power Flow: to calculate the most optimal output of the gas turbines, HRSG and gas-fired boilers while still meeting power system constraints, such as generator active and reactive power limits, transformer taps and bus voltages. Optimal power flow analysis is needed to understand the tradeoff between power system losses, voltage and power-steam dispatch.

\subsubsection{Objective functions}

The objective function is the minimum cost for power and steam generation, while still meeting power system constraints. The total fuel consumption for gas turbines, duct burners and gas-fired boilers is formulated as follows:

a. Total fuel for gas turbine $(\$)$ :

$$
F_{G T}=\sum_{i=1}^{N_{G T}} s_{G T, i}\left[\left(w_{F G, i} L H V_{m, F G, i} p r_{F G}\right)+\left(w_{N G, i} L H V_{m, N G, i} p r_{N G}\right)\right]
$$

where $N_{G T}$ is the total number of gas turbines.

b. Total fuel for duct burners $(\$)$ :

$$
F_{D B}=\sum_{i=1}^{N_{D B}} S_{D B, i}\left(w_{f, D B, i} L H V_{m, N G} p r_{N G}\right)
$$

where $N_{D B}$ is the total number of duct burners.

c. Total fuel for gas-fired boilers $(\$)$ :

$$
F_{G B}=\sum_{i=1}^{N_{G B}} s_{G B, i}\left(w_{f, G B, i} L H V_{m, N G} p r_{N G}\right)
$$

where $N_{G B}$ is the total number of gas boilers.

The objective function can be formulated as:

$$
\min F_{G T}+F_{D B}+F_{G B}
$$

The $s_{G T, i}, s_{D B, i}$ and $s_{G B, i}$ variables are binary numbers, which indicate the running status for gas turbines, duct burners and gas boilers. Thus, the optimization is a mixed integer non-linear programming problem. After securing the status of the gas turbines, duct burners and gas boilers, optimization is refined using the Combined Heat and Power Optimal Power Flow model. The objective function is still the same 
with equation (16)-(18), only the binary variables have been attained from 1 st stage optimization. Natural and field gas prices are assumed to be $5 \$ / \mathrm{GJ}$ and $1 \$ / \mathrm{GJ}$, respectively.

\subsubsection{Constraints}

The constraints for $1^{\text {st }}$ stage optimization are:

a. Spinning reserve

$$
P_{\text {load }}^{\text {peak }} \leq \sum_{i=1}^{N_{G T}} P_{G T, i}^{\max }+S R
$$

b. Real power balance

$$
\sum_{i=1}^{N_{G T}} P_{G T, i}=P_{l o a d}
$$

c. Steam demand and supply balance

$$
\sum_{i=1}^{N_{H R S G}} W_{S V H, i}+\sum_{i=1}^{N G B} W_{S V B, i} \geq W_{S V D}
$$

where $N_{H R S G}$ is the total number of HRSG.

d. Real power capability limit

$$
P_{G T, i}^{\min } \leq P_{G T, i} \leq P_{G T, i}^{\max }
$$

e. Field gas availability limit

$$
V_{F G, i} \leq V_{F G, i}^{\max }
$$

f. Steam production capability limit

$$
W_{S, i}^{\min } \leq W_{S, i} \leq W_{S, i}^{\max }
$$

g. Turbine inlet temperature

$$
T_{f, i}^{\min } \leq T_{f, i} \leq T_{f, i}^{\max }
$$

h. Fuel mass flow limit

$$
w_{f, i}^{\min } \leq w_{f, i} \leq w_{f, i}^{\max }
$$

The above (21)-(26) constraints are still maintained in the $2^{\text {nd }}$ stage of optimization, with the following additional constraints:

i. Power Flow Balance

$$
\begin{aligned}
& P_{G T, i}-P_{\text {load }, i}-\sum_{j \in i} P_{i}^{i n j}=0 \\
& Q_{G T, i}-Q_{\text {loa }, i}-\sum_{j \in i} Q_{i}^{i n j}=0 \\
& P_{i}^{i n j}=V_{i}^{2} G_{i i}+V_{i} V_{j}\left[G_{i j} \cos \left(\theta_{i}-\theta_{j}\right)+B_{i j} \sin \left(\theta_{i}-\theta_{j}\right)\right] \\
& Q_{i}^{i n j}=-V_{i}^{2} B_{i i}+V_{i} V_{j}\left[G_{i j} \sin \left(\theta_{i}-\theta_{j}\right)-B_{i j} \cos \left(\theta_{i}-\theta_{j}\right)\right]
\end{aligned}
$$

j. Reactive power capability limit

$$
Q_{G T, i}^{\min } \leq Q_{G T, i} \leq Q_{G T, i}^{\max }
$$


k. Voltage levels

$$
V_{i}^{\min } \leq V_{i} \leq V_{i}^{\max }
$$

1. Limit of transformer tap changer

$$
T_{t x, i}^{\min } \leq T_{t x, i} \leq T_{t x, i}^{\max }
$$

For unit commitment analysis, the model uses the BONMIN solver [33] which is provided in OPTI [34], a MATLAB-based optimization add-in. For the Combined Heat and Power Optimal Power Flow, the model uses three solvers: Interior Point (IPOPT) [35] provided in OPTI, Active Set (MATLAB Optimization Toolbox) and Sequential Quadratic Programming, provided in TOMLAB. These solvers are used for comparison purposes.

Case studies are simulated based on steam and electrical load. Steam demand for high, medium and low categories are 2,319;1,656 and $662 \mathrm{~m}^{3}$ cold water equivalent per hour, respectively. Electrical load for high and low categories are 450 and $350 \mathrm{MW}$. Thus, the simulation covers six scenarios, as follows:

a. Scenario 1: high steam demand and high electrical load

b. Scenario 2: medium steam demand, high electrical load

c. Scenario 3: low steam demand, high electrical load

d. Scenario 4: high steam demand and low electrical load

e. Scenario 5: medium steam demand, low electrical load

f. Scenario 6: low steam demand, low electrical load

\section{RESULTS AND ANALYSIS}

First, we discuss the unit commitment result shown in Table 3, which calculates the number of gas turbines running. DG-Type 1 gas turbines have the lowest heat rate; thus they are the most efficient. Furthermore, these units can also deliver steam. Hence, it is recommended that all three DG Type 1 gas turbines run in every scenario.

Table 3. Number of Gas Turbine Running

\begin{tabular}{ccccccc}
\hline Scenario & $\begin{array}{c}\text { High Steam- } \\
\text { High Load }\end{array}$ & $\begin{array}{c}\text { Med. Steam- } \\
\text { High Load }\end{array}$ & $\begin{array}{c}\text { Low Steam- } \\
\text { High Load }\end{array}$ & $\begin{array}{c}\text { High Steam- } \\
\text { Low Load }\end{array}$ & $\begin{array}{c}\text { Med Steam- } \\
\text { Low Load }\end{array}$ & $\begin{array}{c}\text { Low Steam- } \\
\text { Low Load }\end{array}$ \\
\hline DG - Gas Turbine Type 1 & 3 & 3 & 3 & 3 & 3 & 3 \\
AG - Gas Turbine Type 2 & 5 & 5 & 2 & 3 & 2 & 2 \\
MG- Gas Turbine Type 3 & 1 & 1 & 1 & 0 & 0 & 1 \\
MG- Gas Turbine Type 2 & 0 & 0 & 2 & 0 & 2 & 0 \\
MG - Gas Turbine Type 4 & 3 & 3 & 3 & 2 & 8 & 8 \\
Total Unit & 12 & 12 & 11 & 8 & & 2 \\
\hline
\end{tabular}

AG Type 2 gas turbines are always prioritized to run due to their steam production capabilities. AG Type 2 is only less prioritized when the steam demand is low. MG Type 4 gas turbines are the second most efficient. During high load scenarios, it is recommended that all three run. In low load scenarios, $\mathrm{MG}$ Type 4 priority becomes lower/similar with AG Type 2 units, which have higher heat rate but are capable of producing steam.

Only one out of five MG-Type 3 units that is recommended to run in most scenarios. Even though MG Type 3 is the least efficient unit, it still has higher prioritization compared to the other gas turbines which have lower heat rates. This prioritization is due to the availability of dedicated field gas for MG-Type 3, as shown in Table 2. Further simulation shows that the power dispatch for MG Type 3 is equal to its available field gas supply.

Figure 2 shows the real power dispatch. DG Type 1 units are running on base load in all scenarios due to their low heat rate. AG Type 2 can produce steam and their power dispatch depends on the steam demand. MG units, which do not have a steam production capability, only provide an additional power supply to meet electrical load demand.

All MG units' power dispatch increases significantly in low steam demand scenarios. Table 4 shows that there is a significant change in power system losses in low steam demand scenario. As shown in Appendix Tables 10 and Table 11, the majority of the load is in F, G, H, I, J, K, L, M substations, which are located closer to the MG units. When steam demand is low, there is no need to generate much power from 
AG. Thus, the optimization model would rather prioritize MG units, which are located close to the load center, to significantly reduce power system losses.

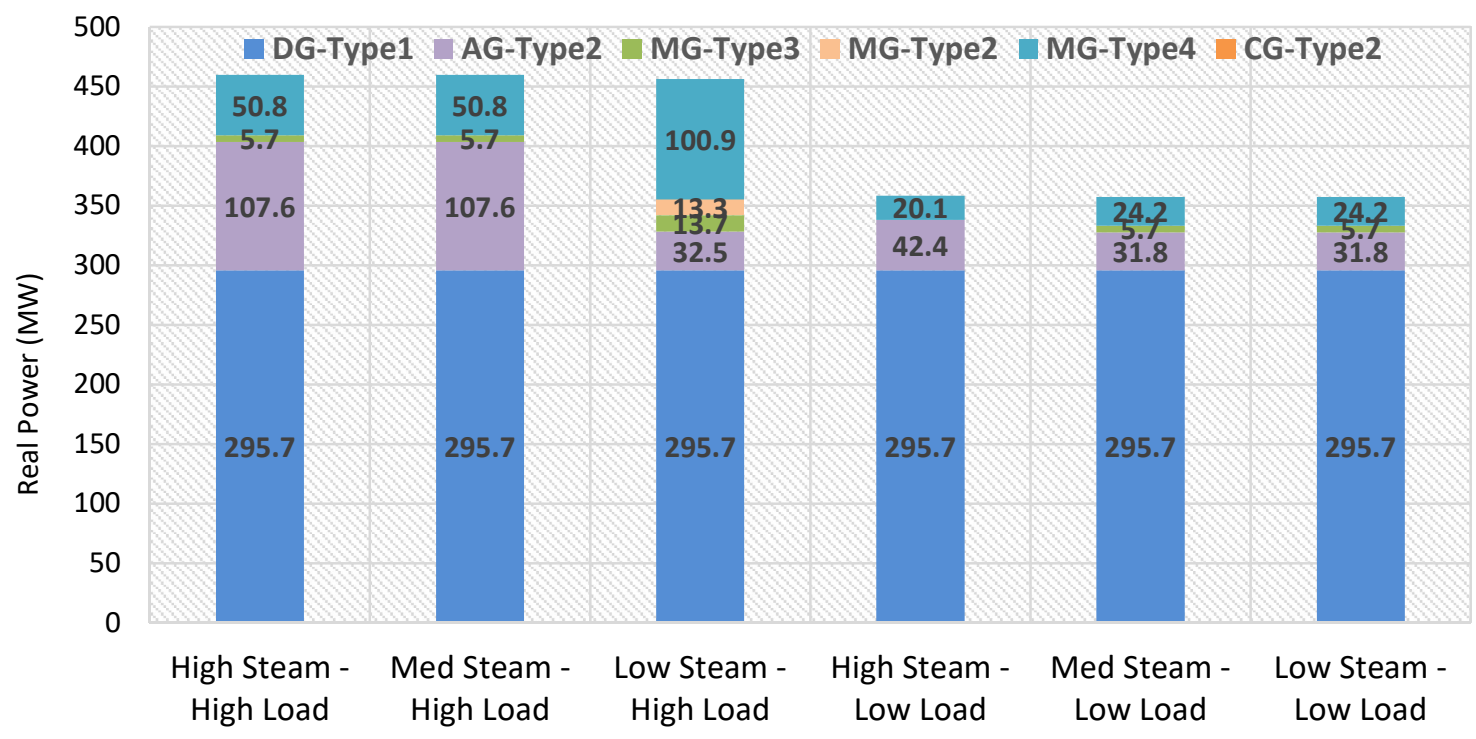

Figure 2. Real power dispatch (MW)

Table 4. Power System Losses (MW)

\begin{tabular}{lcccccc}
\hline \multirow{2}{*}{ Scenario } & $\begin{array}{l}\text { High Steam }- \\
\text { High Load }\end{array}$ & $\begin{array}{l}\text { Med. Steam }- \\
\text { High Load }\end{array}$ & $\begin{array}{l}\text { Low Steam }- \\
\text { High Load }\end{array}$ & $\begin{array}{l}\text { High Steam }- \\
\text { Low Load }\end{array}$ & $\begin{array}{l}\text { Med Steam }- \\
\text { Low Load }\end{array}$ & $\begin{array}{l}\text { Low Steam - } \\
\text { Low Load }\end{array}$ \\
\hline Losses & 9.45 & 9.45 & 5.78 & 7.92 & 7.05 & 7.05 \\
\hline
\end{tabular}

Table 5 and Table 6 show the optimal fuel composition in terms of volumetric flow and mixture ratio, respectively. As shown in Table 2, the available field gas production from AG units is 15,612 standard $\mathrm{m}^{3}$ per hour. Table 5 shows that AG units utilize all available field gas in all scenarios. Steam production from AG units depends on their power dispatch. Natural gas acts as a "back up" fuel to provide additional power output to meet steam demand. During low steam demand, natural gas consumption decreases significantly.

Table 5. Fuel Volumetric Flow (Standard $\mathrm{m}^{3}$ per Hour)

\begin{tabular}{lcccccc}
\hline \multirow{2}{*}{ Scenario } & \multicolumn{2}{c}{ AG Type 2 } & \multicolumn{2}{c}{ MG Type 3 } & \multicolumn{2}{c}{ MG Type 2\&4 } \\
& NG & FG & NG & FG & NG & FG \\
\hline High Steam - High Load & 30,813 & 15,612 & 0 & 4,130 & 7,671 & 17,615 \\
Med Steam - High Load & 30,813 & 15,612 & 0 & 4,130 & 7,671 & 17,615 \\
Low Steam - High Load & 1,250 & 15,612 & 2,831 & 4,130 & 30,181 & 16,493 \\
High Steam - Low Load & 6,810 & 15,612 & 0 & 0 & 0 & 13,458 \\
Med Steam - Low Load & 1,044 & 15,612 & 0 & 4,130 & 0 & 15,265 \\
Low Steam - Low Load & 1,044 & 15,612 & 0 & 4,130 & 0 & 15,265 \\
\hline NG= Natural Gas FG = Field Gas & & & & &
\end{tabular}

Table 6. Optimal Mixture of Consumed Natural Gas: Field Gas by Volume

\begin{tabular}{ccccccc}
\hline \multirow{2}{*}{ Scenario } & $\begin{array}{c}\text { High Steam }- \\
\text { High Load }\end{array}$ & $\begin{array}{c}\text { Med. Steam - } \\
\text { High Load }\end{array}$ & $\begin{array}{c}\text { Low Steam }- \\
\text { High Load }\end{array}$ & $\begin{array}{c}\text { High Steam - } \\
\text { Low Load }\end{array}$ & $\begin{array}{c}\text { Med Steam - } \\
\text { Low Load }\end{array}$ & $\begin{array}{c}\text { Low Steam - } \\
\text { Low Load }\end{array}$ \\
\hline AG Type2 & $66 \%: 34 \%$ & $66 \%: 34 \%$ & $7 \%: 93 \%$ & $30 \%: 70 \%$ & $6 \%: 94 \%$ & $6 \%: 94 \%$ \\
MG Type 3 & $0 \%: 100 \%$ & $0 \%: 100 \%$ & $41 \%: 59 \%$ & $0 \%: 0 \%$ & $0 \%: 100 \%$ & $0 \%: 100 \%$ \\
MG Type 2\&4 & $30 \%: 70 \%$ & $30 \%: 70 \%$ & $65 \%: 35 \%$ & $0 \%: 100 \%$ & $0 \%: 100 \%$ & $0 \%: 100 \%$ \\
\hline
\end{tabular}


MG Type 3 units are the most inefficient unit based on heat rate value. In most scenarios, power dispatch on MG-Type 3 is recommended at 5.7 MW. The available field gas for MG Type 3 based on Table 2 is 4,130 standard $\mathrm{m}^{3}$ per hour. Table 5 and Table 6 show that in most scenarios, MG-Type 3 consumes only the available field gas production, without consuming additional natural gas. Thus, this unit is running merely to consume field gas in the majority of scenarios. This result shows that apart from heat rate, low cost field gas availability also affects power dispatch optimization. Inefficient units can be dispatched at the exact amount of equivalent available field gas energy.

A different condition is found in the low steam-high load scenario. The optimization model recommends MG Type 3 consumes natural gas, with the purpose of boosting MG Type 3 output. As stated in the previous section, boosting the power output from MG units, including Type 3, will have a significant impact on loss reduction. In the high steam-low load scenario, it is not recommended that MG Type 3 to run. In this scenario, units that are capable to produce steam are prioritized. With high heat rate values, Type 3 is the unit given the lowest priority.

MG Type 2 and Type 4 share the same field gas supply, as shown in Table 2. In the first two scenarios (high steam-high load and med steam-high load), field gas becomes the priority fuel. However, in low steam-high load scenarios, the optimization model chooses natural gas instead of using all the available field gas. Since natural gas has a better LHV value, selecting natural gas boosts the output of MG Type 4 and Type 2. Since MG units are closer to the load center, boosting the power output of MG Type 4 and 2 reduces power system losses significantly from 9.47 to $5.78 \mathrm{MW}$, as shown in Table 4.

In all low loads scenarios, MG Type 2 and 4 only consume field gas. However, the consumed volume is less than the maximum available volume stated in Table 2. During low load scenarios, units that are capable of producing steam still have significant power dispatch to boost steam production. The remaining load that is supplied from MG Type 2 and 4 is not enough to consume all available field gas. Table 7 summarizes the percentage of total utilized field gas compared to available field gas production. Of the six scenarios, it is only in the high steam-high load and medium steam-high load scenarios that all the available field gas production is utilized as fuel.

Table 7. Percentage of Field Gas Utilization by Volume in Each Scenario

\begin{tabular}{lcccccc}
\hline \multirow{2}{*}{ Scenario } & $\begin{array}{c}\text { High Steam } \\
\text { - High Load }\end{array}$ & $\begin{array}{c}\text { Med. Steam } \\
\text { - High Load }\end{array}$ & $\begin{array}{c}\text { Low Steam } \\
\text { - High Load }\end{array}$ & $\begin{array}{c}\text { High Steam } \\
\text { - Low Load }\end{array}$ & $\begin{array}{c}\text { Med Steam } \\
\text { - Low Load }\end{array}$ & $\begin{array}{c}\text { Low Steam } \\
\text { - Low Load }\end{array}$ \\
\hline Utilized Field Gas $\mathrm{m}^{3} / \mathrm{hr} @$ STD & 37,357 & 37,357 & 36,235 & 29,070 & 35,006 & 35,006 \\
Available Field Gas $\mathrm{m}^{3} / \mathrm{hr} @$ STD & 37,357 & 37,357 & 37,357 & 37,357 & 37,357 & 37,357 \\
Field Gas \% Utilization & $100 \%$ & $100 \%$ & $97 \%$ & $78 \%$ & $94 \%$ & $94 \%$ \\
\hline
\end{tabular}

Figure 3 shows that steam demand has a significant impact on power system voltage quality. To boost steam production, power dispatch on DG and AG units must be increased. These units are located remotely from the load center. Thus, during high and medium steam demand, power system losses tend to be higher compared to the low steam demand scenario. This causes the voltage profile in high and medium steam demand scenarios to be lower compared to low demand scenario.

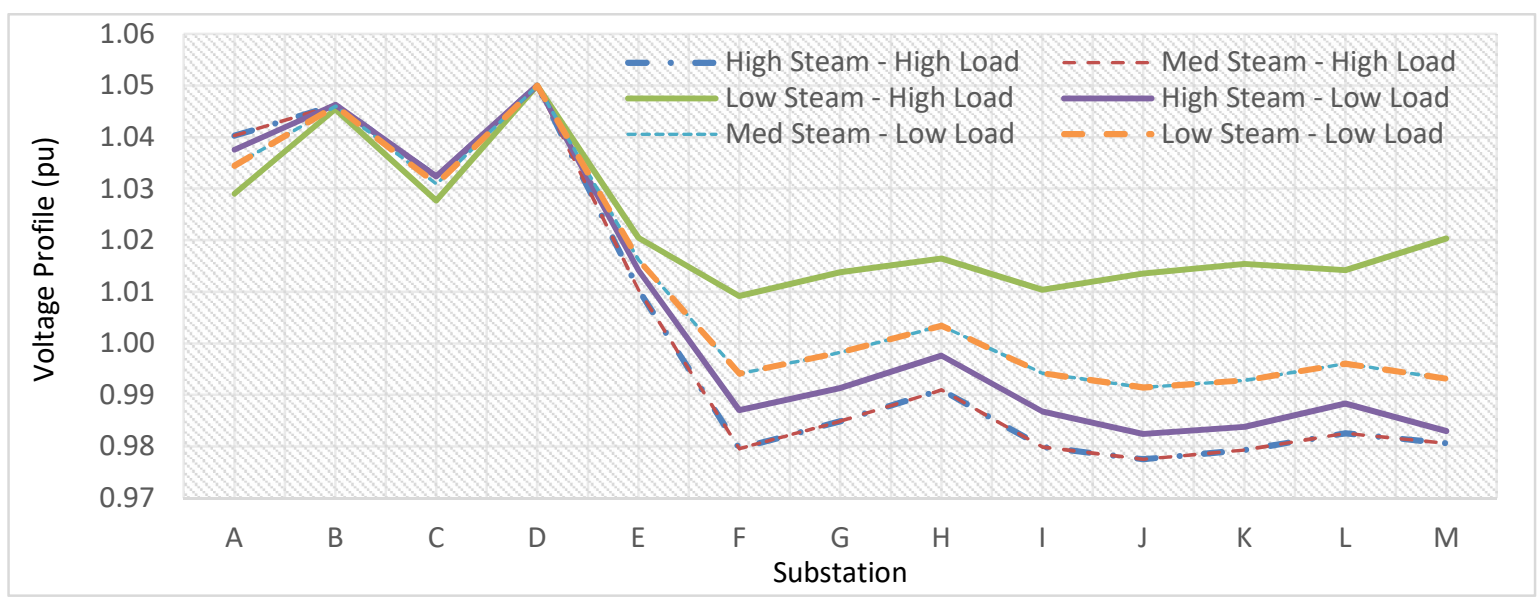

Figure 3. Voltage profile (per unit) 
Steam production from HRSG, HRSG-DB and GB is shown in Table 8. It is recommended that GBs run only in high steam demand scenarios. Table 9 shows the objective function in each scenario. All three solvers produce the same optimal cost in all scenarios.

Table 8. Steam Output $\left(\mathrm{m}^{3} /\right.$ hour $)$

\begin{tabular}{lcccccc}
\hline \multirow{2}{*}{ Scenario } & $\begin{array}{l}\text { High Steam }- \\
\text { High Load }\end{array}$ & $\begin{array}{l}\text { Med. Steam }- \\
\text { High Load }\end{array}$ & $\begin{array}{l}\text { Low Steam }- \\
\text { High Load }\end{array}$ & $\begin{array}{l}\text { High Steam }- \\
\text { Low Load }\end{array}$ & $\begin{array}{l}\text { Med Steam }- \\
\text { Low Load }\end{array}$ & $\begin{array}{c}\text { Low Steam }- \\
\text { Low Load }\end{array}$ \\
\hline DG & 1,829 & 1,346 & 793 & 1,829 & 1,553 & 793 \\
AG & 311 & 311 & 104 & 145 & 103 & 103 \\
GB & 179 & 0 & 0 & 345 & 0 & 0 \\
\hline
\end{tabular}

Table 9. Optimal Cost (\$/hour)

\begin{tabular}{lcrrrrr}
\hline \multirow{2}{*}{ Scenario } & $\begin{array}{l}\text { High Steam }- \\
\text { High Load }\end{array}$ & $\begin{array}{l}\text { Med. Steam }- \\
\text { High Load }\end{array}$ & $\begin{array}{l}\text { Low Steam }- \\
\text { High Load }\end{array}$ & $\begin{array}{l}\text { High Steam - } \\
\text { Low Load }\end{array}$ & $\begin{array}{l}\text { Med Steam - } \\
\text { Low Load }\end{array}$ & $\begin{array}{l}\text { Low Steam }- \\
\text { Low Load }\end{array}$ \\
\hline OPTI & 37,075 & 29,781 & 22,935 & 33,092 & 25,410 & 17,050 \\
Matlab & 37,075 & 29,781 & 22,935 & 33,092 & 25,410 & 17,050 \\
Tomlab & 37,075 & 29,781 & 22,935 & 33,092 & 25,410 & 17,050 \\
\hline
\end{tabular}

\section{CONCLUSION}

This paper presented an optimization model based on mixed integer nonlinear programming which can analyze the tradeoff between cost, steam production, losses and field gas utilization. The utilization of multiple fuel streams is a unique problem, the fuel mixture must be optimized to achieve the lowest fuel cost. The unit commitment result is not solely dependent on heat rate; rather, it also depends on field gas availability. A less efficient unit can be prioritized to run if there is a sufficient amount of field gas supply.

There is a strong relationship between power dispatch, steam dispatch, field gas utilization and power system losses. With high steam demand, high losses are accepted as a consequence of maximizing steam production from gas turbines with HRSG. Steam demand also has a significant impact on power system voltage quality. Since the majority of the load is far from the steam-producing gas turbines, the voltage profile in high steam demand scenarios is lower compared to low steam demand scenarios.

The simulation is able to find the most optimal fuel mixture. The optimal mixture does not always mean that all available low-cost field gas must be consumed. This demonstrates that there is a need to limit field gas production to just the right amount to avoid over production and ensure optimal cost. The optimization model is also able to give the most optimal steam dispatch to HRSG, HRSG-DB and GB. The simulation shows that GB is the least prioritized steam producer.

The case studies in this work only focus on single objective optimization. For future work, this can be expanded to multi-objective optimization, with cost vs. loss, cost vs. emission or cost vs. system voltage stability as the objective functions. Regarding gas, this research only focuses on gas volume. In future work, this can be expanded to handle constraints in the gas distribution network.

\section{REFERENCES}

[1] E.D. Attanasi, P.A. Freeman, "Role of Stranded Gas In Increasing Global Gas Supplies," United States Geological Survey, 2013, 57 p., Open File Report 2013-1044

[2] N.B. Anosike, "Techno-economic Evaluation of Flared Natural Gas Reduction And Energy Recovery Using Gas to Wire Scheme," Ph.D. dissertation, School of Eng. Power \& Propulsion Dept., Cranfield University, 2013

[3] R. Khalilpour, I.A. Karimi, "Evaluation of Utilization Alternatives for Stranded Natural Gas," Energy, vol. 40, pp. 317-328, Jan 2012

[4] M. M. Zyranova et al, "Upgrading of Associated Petroleum Gas Into Methane-Rich Gas for Power Plant Feeding Applications: Technological and Economic Benefits,” Fuel, vol. 108, pp. 282-291, Jun 2013.

[5] S.D. Panjaitan, Yandri, Sukandar, B. Sitorus, "Comparative Study of Electricity Generation Fueled by Gasoline, Liquefied Petroleum Gas and Biogas from Municipal Solid Waste", International Journal of Electrical and Computer Engineering, vol. 3 (6), pp. 762-769, Dec 2013

[6] T. Watanabe, H, Inoue, H. Moritsugi, S. Oya, "GTW (Gas to Wire) System for Developing Small Gas Field and Exploiting Associated Gas," SPE International Oil \& Gas Conference \& Exhibition, vol. 1, pp.310-315, 2006

[7] V.S. Arutyunov, "Utilization of Associated Petroleum Gas Via Small Scale Power Generation," Russian Journal of General Chemistry, vol. 81, pp. 2557-2563, Dec 2011.

[8] P.A. Gorbachev, V.G. Mikhailutsa, "Gas Turbine Power Stations on Associated Gas by Motor Sich OJSC," Russian Journal of General Chemistry, vol. 81, pp. 2564-2567, Dec 2011.

[9] A.I. Gur'yanov,"Analysis of the Gas Turbine Engine Combustion Chamber Conversion to Associated Petroleum Gas and Oil”, Russian Aeronautics, vol. 58, pp. 205 - 209, January 2015. 
[10] E. Vanadzina, O. Gore, S. Viljainen and V.P. Tynkkynen, "Electricity Production as an Effective Solution for Associated Petroleum Gas Utilization in the Reformed Russian Electricity Market," in: Proceedings of the 12th International Conference on The European Energy Market, 2015

[11] V. Rajovic, F. Kiss, N. Maravic, O. Bera, "Environmental Flows and Life Cycle Assessment of Associated Petroleum Gas Utilization Via Combined Heat and Power Plants and Heat Boilers at Oil Fields," Energy Conversion \& Management, vol. 118, pp. 96 - 104, Jun 2016.

[12] A. Ahmadi, H. Moghmi," Multi-objective Economic Emission Dispatch Considering Combined Heat and Power by Normal Boundary Intersection Method," Electric Power System Research, vol. 129, pp. 32 - 43, 2015.

[13] F.J.Rooijers, R.A.M. van Amerongen, "Static Economic Dispatch for Co-Generation Systems," IEEE Transactions on Power System, vol. 9, Mar 1994

[14] T. Guo, M. van Ooijen, “An Algorithm for Combined Heat and Power Economic Dispatch," IEEE Transactions on Power System, vol. 4, April 1996

[15] Y.C.S. Song, C.S. Chou, T.J. Stonham, "Combined Heat and Power Economic Dispatch by Improved Ant Colony Search Algorithm," Electr. Power Syst. Research, vol. 52, pp. 115-121, 1999.

[16] K. Wong, C. Algie, "Evolutionary Programming Approach for Combined Heat and Power Dispatch," Electrical Power System Research, vol. 61, 227-232, 2002

[17] M. Abido,"Environmental/Economic Power Dispatch Using Multi-Objective Evolutionary Algorithms," IEEE Transactions on Power System, vol. 18, 2003

[18] L. Wang, L, C. Singh, "Stochastic Combined Heat and Power Dispatch Based on Multi-Objective Particle Swarm Optimization," Electrical Power and Energy Systems, vol. 30, pp. 226 - 234, 2008

[19] P. Subbaraj, R. Rengaraj, S. Salivahanan, "Enhancement of Combined Heat And Power Economic Dispatch Using Self-Adaptive Real-Coded Genetic Algorithm, “Appl. Energy, vol. 86, pp.915-921, 2009

[20] M. Basu, "Bee Colony Optimization for Combined Heat and Power Economic Dispatch," Expert Systems with Applications, vol. 38, pp. 13527-13531, Nov 2011

[21] B. Mohammadi-Ivatloo, M. Moradi-Dalvand, A. Rabiee, "Combined Heat and Power Economic Dispatch Problem Solution Using Particle Swarm Optimization With Time Varying Acceleration Coefficients," Electr. Power Syst. Res., vol. 95, pp, 9-18,Feb 2013

[22] M. Basu, "Combined Heat and Power Economic Dispatch Using Opposition Based Group Search Optimization," Electrical Power and Energy Systems, vol 73, pp. 819 - 829, 2015

[23] C. Jena, M. Basu, C.K. Panigrahi, "Differential Evolution With Gaussian Mutation for Combined Heat and Power Economic Dispatch," Soft Computing, Nov 2014.

[24] S. Derafshi, H. Abdi, M. La, "Combined Heat and Power Economic Dispatch Problem Using Gravitational Search Algorithm,” Electric Power Systems Research, vol. 133, pp. 160-172, 2016

[25] P.K. Hota, N.C. Sahu, "Non-Convex Economic Dispatch with Prohibited Operating Zones through Gravitational Search Algorithm," International Journal of Electrical and Computer Engineering, vol. 5 (6), pp. 1234-1244, Dec 2015

[26] Lahdelma, R., \& Hakonen, H, "An Efficient Linear Programming Algorithm for Combined Heat and Power Production," European Journal of Operational Research, vol. 148, pp. 141-151, Jan 2003

[27] A. Sashirekha, J. Pasupuleti, N.H. Moin, C.S. Tan, "Combined Heat and Power Economic Dispatch Solved Using Lagrangian Relaxation With Surrogate Subgradient Multiplier Updates," Electrical Power and Energy Systems, vol. 44, pp. $421-430,2013$

[28] H. Abdolmohammadi, A. Kazemi, "A Benders Decomposition Approach for A Combined Heat and Power Economic Dispatch,” Energy Conversion and Management, vol. 71, pp. 21-31, 2013

[29] B. Shi, LX Yan, W. Wu, "Multi-Objective Optimization for Combined Heat and Power Economic Dispatch with Power Transmission Loss and Emission Reduction," Energy, vol. 56, 135-143, 2013

[30] E. Abdollahi, H. Wang, R. Lahdelma, R., "An Optimization Method for Multi-Area Combined Heat and Power Production With Power Transmission Network," Applied Energy, vol. 168,pp. 248-256, 2016

[31] J.S. Kim, T.F. Edgar, "Optimal Scheduling of Combined Heat and Power Plants Using Mixed Integer Nonlinear Programming," Energy, pp. 1-16, 2014

[32] I. Abdou, M. Tkiouat, "Unit Commitment Problem in Electrical Power System: a Literature Review," International Journal of Electrical and Computer Engineering, vol. 8 (3), pp. 1357-1372, June 2018

[33] P. Bonami, "An Algorithmic Framework for Convex Mixed Integer Nonlinear Programs," Discrete Optimization, vol. 5, pp. 186-204, 2008

[34] Currie, J., D.I. Wilson, "OPTI: Lowering the Barrier Between Open Source Optimizers and the Industrial MATLAB User," in: Proceedings of the Foundations of Computer-Aided Process Operations, Jan 2012

[35] A. Wächter, L. T. Biegler, "On the Implementation of a Primal-Dual Interior Point Filter Line Search Algorithm for Large-Scale Nonlinear Programming,” Mathematical Programming, vol. 106, pp. 25-57, Jan 2006

Int J Elec \& Comp Eng, Vol. 9, No. 1, February 2019 : 42 - 54 


\section{APPENDIX}

Table 10. Transmission Line Parameter

\begin{tabular}{|c|c|c|c|c|c|c|c|c|c|c|c|}
\hline Line & $\begin{array}{c}\text { Distance } \\
(\mathrm{km})\end{array}$ & $\mathrm{Z}(\Omega)$ & $\begin{array}{c}\text { Angle } \\
\text { (deg) }\end{array}$ & Line & $\begin{array}{c}\text { Distance } \\
(\mathrm{km})\end{array}$ & $Z(\Omega)$ & $\begin{array}{l}\text { Angle } \\
\text { (deg) }\end{array}$ & Line & $\begin{array}{c}\text { Distance } \\
(\mathrm{km})\end{array}$ & $\mathrm{Z}(\Omega)$ & $\begin{array}{l}\text { Angle } \\
\text { (deg) }\end{array}$ \\
\hline A-D & 10 & 3.64 & 75.15 & D-H' & 70 & 13.4 & 75.95 & G-H & 8.5 & 3.09 & 75.15 \\
\hline A-C & 8.4 & 2.21 & 69.33 & E-H & 27 & 14.2 & 69.33 & $\mathrm{H}-\mathrm{I}$ & 14.6 & 5.31 & 75.15 \\
\hline B-D & 4.4 & 1.6 & 75.15 & F-I & 3.1 & 1.63 & 69.33 & H-L & 12.6 & 4.58 & 75.15 \\
\hline B-C & 17.6 & 6.4 & 75.15 & F-H & 12.5 & 6.59 & 69.33 & I-J & 6.76 & 3.56 & 69.33 \\
\hline C-E & 24 & 12.6 & 69.33 & G-L & 4.4 & 2.32 & 69.33 & $\mathrm{~J}-\mathrm{M}$ & 4.8 & 2.53 & 69.33 \\
\hline $\mathrm{C}-\mathrm{H}$ & 51 & 26.9 & 69.33 & D-H ba & voltage is & $30 \mathrm{kV}, \mathrm{c}$ & ner lines & base vo & ge is $115 \mathrm{k}$ & & \\
\hline
\end{tabular}

Table 11. Substation Load

\begin{tabular}{ccccccccc}
\hline Subs. & $\begin{array}{c}\mathrm{P}_{\text {load }} \\
(\mathrm{MW})\end{array}$ & $\begin{array}{c}\mathrm{Q}_{\text {load }} \\
(\mathrm{MVAR})\end{array}$ & Subs. & $\begin{array}{c}\mathrm{P}_{\text {load }} \\
(\mathrm{MW})\end{array}$ & $\begin{array}{c}\mathrm{Q}_{\text {load }} \\
(\mathrm{MVAR})\end{array}$ & Subs. & $\begin{array}{c}\mathrm{P}_{\text {load }} \\
(\mathrm{MW})\end{array}$ & $\begin{array}{c}\mathrm{Q}_{\text {load }} \\
(\mathrm{MVAR})\end{array}$ \\
\hline $\mathrm{A}$ & 67.5 & 37.9 & $\mathrm{E}$ & 3 & 2.7 & $\mathrm{~J}$ & 24.1 & 16.7 \\
$\mathrm{AG}$ & 52.1 & 35.4 & $\mathrm{~F}$ & 23.5 & 17.1 & $\mathrm{~K}$ & 20.4 & 11 \\
$\mathrm{~B}$ & 1 & 0.5 & $\mathrm{G}$ & 22.3 & 9.4 & $\mathrm{~L}$ & 22.6 & 16.9 \\
$\mathrm{C}$ & 37 & 25.3 & $\mathrm{H}$ & 47.7 & 23.2 & $\mathrm{M}$ & 59.8 & 35.4 \\
$\mathrm{D}$ & 17.2 & 14.7 & $\mathrm{I}$ & 20.1 & 13.2 & $\mathrm{MG} 1$ & 32.09 & 16.05 \\
\hline
\end{tabular}

Table 12. Transformer Data

\begin{tabular}{|c|c|c|c|c|c|c|c|c|c|c|c|}
\hline $\begin{array}{c}\text { Transfo } \\
\text { rmer }\end{array}$ & $\begin{array}{c}\text { \# of } \\
\text { Units }\end{array}$ & $\begin{array}{c}\text { Base/Max } \\
\text { Capacity } \\
\text { (MVA) }\end{array}$ & $\begin{array}{c}Z \\
(\%)\end{array}$ & $\begin{array}{c}\text { Transfo } \\
\text { rmer }\end{array}$ & $\begin{array}{c}\text { \# of } \\
\text { Units }\end{array}$ & $\begin{array}{c}\text { Base/Max } \\
\text { Capacity } \\
\text { (MVA) }\end{array}$ & $\begin{array}{c}Z \\
(\%)\end{array}$ & $\begin{array}{c}\text { Transfor } \\
\text { mer }\end{array}$ & $\begin{array}{l}\text { \# of } \\
\text { Units }\end{array}$ & $\begin{array}{c}\text { Base/Max } \\
\text { Capacity } \\
\text { (MVA) }\end{array}$ & $\begin{array}{c}Z \\
(\%)\end{array}$ \\
\hline TD1 & 1 & $90 / 150$ & 10 & TM1 & 3 & $12 / 22$ & 8 & TA & 5 & $15 / 28$ & 9 \\
\hline TD2 & 1 & $90 / 150$ & 10 & TM2 & 3 & $25 / 25$ & 7.6 & $\mathrm{TC}$ & 1 & $15 / 28$ & 8 \\
\hline TD3 & 3 & $90 / 150$ & 7 & TM3 & 3 & $42 / 42$ & 7.6 & $\mathrm{TH}$ & 2 & $90 / 250$ & 19 \\
\hline
\end{tabular}

Table 13. Gas Turbine Data

\begin{tabular}{cccccccccc}
\hline \multirow{2}{*}{ Parameter } & $\begin{array}{c}\text { GT } \\
\text { Type 1 }\end{array}$ & $\begin{array}{c}\text { GT } \\
\text { Type 2 }\end{array}$ & $\begin{array}{c}\text { GT } \\
\text { Type 3 }\end{array}$ & $\begin{array}{c}\text { GT } \\
\text { Type 4 }\end{array}$ & Parameter & $\begin{array}{c}\text { GT } \\
\text { Type 1 }\end{array}$ & $\begin{array}{c}\text { GT } \\
\text { Type 2 }\end{array}$ & $\begin{array}{c}\text { GT } \\
\text { Type 3 }\end{array}$ & $\begin{array}{c}\text { GT } \\
\text { Type 4 }\end{array}$ \\
\hline$\theta_{\min }$ & 34 & 34 & 34 & 34 & $\gamma_{\mathrm{c}}$ & 1.4 & 1.4 & 1.4 & 1.4 \\
$\theta_{\max }$ & 85 & 85 & 85 & 85 & $\gamma_{\mathrm{h}}$ & 1.309 & 1.309 & 1.309 & 1.309 \\
$\mathrm{PR}$ & 13.53 & 9.81 & 5.21 & 11.14 & $\mathrm{C}_{\mathrm{pc}}$ & 1.005 & 1.005 & 1.005 & 1.005 \\
$\mathrm{~V}_{\mathrm{cn}}$ & 30000 & 10000 & 7850 & 11345 & $\mathrm{C}_{\mathrm{ph}}$ & 1.16 & 1.16 & 1.16 & 1.16 \\
$\mathrm{~W}_{\mathrm{cn}}$ & 355.65 & 122 & 89.1 & 139 & $\mathrm{~T}_{\mathrm{f}}$ max & 1533 & 1366 & 1377 & 1599 \\
$\mathrm{~W}_{\mathrm{f}, \mathrm{GTn}}$ & 6.55 & 2.15 & 1.72 & 2.7232 & $\mathrm{~T}_{\mathrm{e}}{ }^{\max }$ & 801 & 777 & 777 & 836 \\
$\eta_{\mathrm{c}}$ & $79 \%$ & $81 \%$ & $83 \%$ & $71 \%$ & $\mathrm{\eta}_{\mathrm{comb}}$ & $99 \%$ & $99 \%$ & $99 \%$ & $99 \%$ \\
$\eta_{\mathrm{t}}$ & $91 \%$ & $85 \%$ & $89 \%$ & $93 \%$ & & & & & \\
\hline
\end{tabular}

Table 14. HRSG, Duct Burner, Gas-Fired Boiler Data

\begin{tabular}{cccccccc}
\hline Parameter & HRSG-DB & HRSG & Gas Boiler & Parameter & HRSG-DB & HRSG & GB \\
\hline Wf,DBn $_{\text {f }}$ & 4.7 & 0 & & $\mathrm{~W}_{\mathrm{f}, \mathrm{GBn}}$ & 0 & 0 & 0.472 \\
$\eta_{\mathrm{DB}}$ & 0.99 & - & 0.99 & $\eta_{\mathrm{GB}}$ & & & \\
$\eta_{\mathrm{HRSG}}$ & $92 \%$ & $54 \%$ & & $\mathrm{P}_{\mathrm{EC}}$ & 62 & 75 & 43 \\
$\mathrm{~T}_{\mathrm{SH}}$ & 533 & 542 & 530 & $\mathrm{H}_{\mathrm{SH}}$ & 2297 & 2307 & 2294 \\
$\mathrm{~T}_{\mathrm{EC}}$ & 339 & 352 & 345 & $\mathrm{HEC}$ & 277 & 330 & 301 \\
$\mathrm{~T}_{\mathrm{EX}}$ & 433 & 371 & - & $\mathrm{SQ}$ & $70 \%$ & $61 \%$ & $70 \%$ \\
$\mathrm{P}_{\mathrm{SH}}$ & 35 & 54 & 30 & & & & \\
\hline
\end{tabular}




\section{Nomenclature}

Air molecular weight

Bus angle (deg)

Cold end and hot end ratio specific heat $(\mathrm{J} / \mathrm{molK})$

Combustion chamber, duct burner, gas -fired boiler efficiency (\%)

Compressor air mass flow $(\mathrm{kg} / \mathrm{s})$

Compressor, turbine and HRSG efficiency (\%)

Compressor inlet outlet temperature $(\mathrm{K})$

Compressor inlet pressure (bar)

Conductance and susceptance between bus i and $\mathrm{j}(1 / \Omega)$

Density of field and natural gas at standard condition $\left(\mathrm{kg} / \mathrm{m}^{3}\right)$

Duct burner and gas boiler fuel mass flow $(\mathrm{kg} / \mathrm{s})$

Economizer and steam enthalpy $(\mathrm{kJ} / \mathrm{kg})$

Economizer inlet, steam header temperature (K)

Field \& natural gas price $(\$ / \mathrm{kJ})$

Field \& natural gas mass flow $(\mathrm{kg} / \mathrm{s})$

Gas constant $=8.314 \mathrm{~J} / \mathrm{molK}$

HRSG exhaust temperature $(\mathrm{K})$

Inlet guide vane minimum, maximum, opening angle (Deg)

Low heating value $(\mathrm{kJ} / \mathrm{kg})$

Nominal and actual compressor air volumetric flow $\left(\mathrm{m}^{3} / \mathrm{s}\right)$

Nominal compressor air, duct burner fuel and gas turbine fuel mass flow $(\mathrm{kg} / \mathrm{s})$

Pressure ratio

Reactive power (MVAR)

Specific heat compressor inlet, turbine outlet $(\mathrm{kJ} / \mathrm{kgK})$

Spinning reserve (MW)

Steam demand $\left(\mathrm{m}^{3}\right.$ per second)

Steam header and economizer pressure (bar)

Steam quality $(\%)$

Voltage at bus $\mathrm{i}(\mathrm{kV})$

$\mathrm{MW}_{\text {air }}$

$\theta_{\mathrm{i}}$

$\gamma_{\mathrm{c}}, \gamma_{\mathrm{h}}$

$\eta_{\mathrm{comb}}, \eta_{\mathrm{DB}}, \eta_{\mathrm{GB}}$

$\mathrm{W}_{\mathrm{c}}$

$\eta_{c}, \eta_{t}, \eta_{H R S G}$

$T_{c}, T_{d}$

$\mathrm{P}_{\mathrm{c}}$

$\mathrm{G}_{\mathrm{ij},} \mathrm{B}_{\mathrm{ij}}$

$\rho_{\mathrm{FG}}, \rho_{\mathrm{NG}}$

$\mathrm{W}_{\mathrm{f}, \mathrm{DB}}, \mathrm{W}_{\mathrm{f}, \mathrm{GB}}$

$\mathrm{H}_{\text {,EC }}, \mathrm{H}_{\text {,SH }}$

$\mathrm{T}_{\mathrm{EC}}, \mathrm{T}_{\mathrm{SH}}$

$\mathrm{pr}_{\mathrm{FG}}, \mathrm{pr}_{\mathrm{NG}}$

$\mathrm{W}_{\mathrm{FG}}, \mathrm{W}_{\mathrm{NG}}$

$\mathrm{R}_{\mathrm{g}}$

$\mathrm{T}_{\mathrm{EX}}$

$\theta_{\min }, \theta_{\max }, \theta_{\mathrm{IGV}}$

$\mathrm{LHV}_{\mathrm{m}}$

$\mathrm{V}_{\mathrm{cn}}, \mathrm{V}_{\mathrm{c}}$

$\mathrm{W}_{\mathrm{cn},}, \mathrm{W}_{\mathrm{f}, \mathrm{DBn}}, \mathrm{W}_{\mathrm{f}, \mathrm{GTn}}$

PR

$\mathrm{Q}_{\mathrm{GT}}$

$\mathrm{C}_{\mathrm{pc}}, \mathrm{C}_{\mathrm{ph}}$

SR

$\mathrm{W}_{\mathrm{SVD}}$

$\mathrm{P}_{\mathrm{SH}}, \mathrm{P}_{\mathrm{EC}}$

SQ

$\mathrm{V}_{\mathrm{i}}$ 